\title{
Voltage sags: energy and severity index assessment
}

\section{Hundimientos de tensión: evaluación de su energía y su severidad}

\author{
Santiago Arias-Guzmán ${ }^{1 \mathrm{a}}$, Armando Ustáriz-Farfán ${ }^{1 \mathrm{~b}}$, Eduardo Cano-Plataa ${ }^{\text {1c }}$, Alejandro Gil-Restrepo ${ }^{1 \mathrm{~d}}$, \\ Carlos Rojas-Montano ${ }^{1 \mathrm{e}}$, Juan Orozco-Clavijo ${ }^{1 \mathrm{f}}$, Andrés Guerrero-Guerreroo ${ }^{1 \mathrm{~g}}$, Óscar Ruiz-Guzmán ${ }^{\text {1h }}$
}

\begin{abstract}
${ }^{1}$ Grupo de Investigación en Calidad de la Energía y Electrónica de Potencia (Gicep), Grupo de Investigación en Redes de Distribución y Potencia (GREDyP), Departamento de Ingeniería Eléctrica, Universidad Nacional de Colombia, Colombia. Email: ${ }^{a}$ saariasgu@unal.edu.co, ${ }^{\mathrm{b}}$ ajustarizf@unal.edu.co, ${ }^{\mathrm{c}}$ eacanopl@unal.edu.co, ${ }^{\mathrm{d}}$ algilre@unal.edu.co,

e cdrojasm@unal.edu.co, ${ }^{\mathrm{f}}$ judorozcocl@unal.edu.co, ${ }^{\mathrm{g}}$ afguerrerog@unal.edu.co, ${ }^{\mathrm{h}}$ oaruizg@unal.edu.co
\end{abstract}

Received: 25 January 2018. Accepted: 23 April 2018. Final version: 22 June 2018.

\begin{abstract}
An estimate of the energy not supplied by the network operator is made to quantify users affected by voltage sags. The calculation method imposed by the normative to evaluate the effect of voltage sags does not contemplate the dynamic behavior of this disturbance. Therefore, this research proposes a method of tensor analysis that verifies the unbalance between phases, the existence of various segments and the number of affected phases in voltage sags. As a result, an analysis of the indicators of sags calculated for a database of the network operator using the normative and the proposed method is presented. These results give recommendations to the national regulations in order to identify the requirements in the quantification of the impact generated by voltage sags.
\end{abstract}

Keywords: energy; sag duration; severity; voltage sag.

\section{Resumen}

Para evaluar la cantidad de usuarios afectados por los hundimientos de tensión, se realiza una estimación de la energía no suministrada por el operador de red. Los hundimientos de tensión poseen un comportamiento dinámico, lo cual no es considerado por el método de cálculo impuesto por la normativa para evaluar sus efectos en la red. Por este motivo, esta investigación propone una metodología de análisis tensorial de hundimientos de tensión, que verifica el desbalance entre fases, la existencia de varios segmentos y la cantidad de fases afectadas. Como resultado, se presenta un análisis de los indicadores de hundimientos calculados para una base de datos del operador de red local utilizando la normativa y la metodología propuesta. Estos resultados son un insumo a las regulaciones nacionales para identificar los requerimientos en la cuantificación del impacto que generan los hundimientos de tensión.

Palabras clave: duración hundimiento; energía; hundimiento de tensión; severidad.

\section{Introduction}

Industrial and commercial operation processes are affected by disturbances in the electric service. Among these disturbances, voltage sags cause the most number of problematics like equipment interruptions [1-3].
The analysis of these interruptions generated by voltage sags can be done through different approaches [4].
These approaches allow to list the effects of voltage sags in power systems, a specific point of the system [5-7] and the load behavior in front of a sag [8-9]. Additionally, also allows to relate the disturbance source location in the power system [10]. 
The approach of this article focuses in the assessment of disturbance effects in a specific point of the system through severity and energy index.

An estimate of the energy loss by the network operator is performed to calculate the number of users affected by voltage sags. This is achieved by the indicators of energy and severity of voltage sags [1]. To calculate these indicators, the duration and the residual voltage of each sag are the input parameters [1], [11].

Recent research has identified that the process imposed by the regulations to calculate the duration and the residual voltage does not contemplate some characteristics of the sags [12] - [13].
Among these are: imbalance between phases, multiple segments in the same sag (multistate) and the identification the involved phases.

An example of this type of behavior is shown in the sag of Figure 1. This sag has several segments with variations of the affected phases and residual voltage.

The regulation considers for the calculation of the severity and energy indicators the lowest residual voltage and the duration of the whole voltage sag [1].

For the voltage sag of Figure 1, the indicators computed with the method given by the normative will not reflect its dynamic behavior in the system, affecting the interpretation of this disturbance.

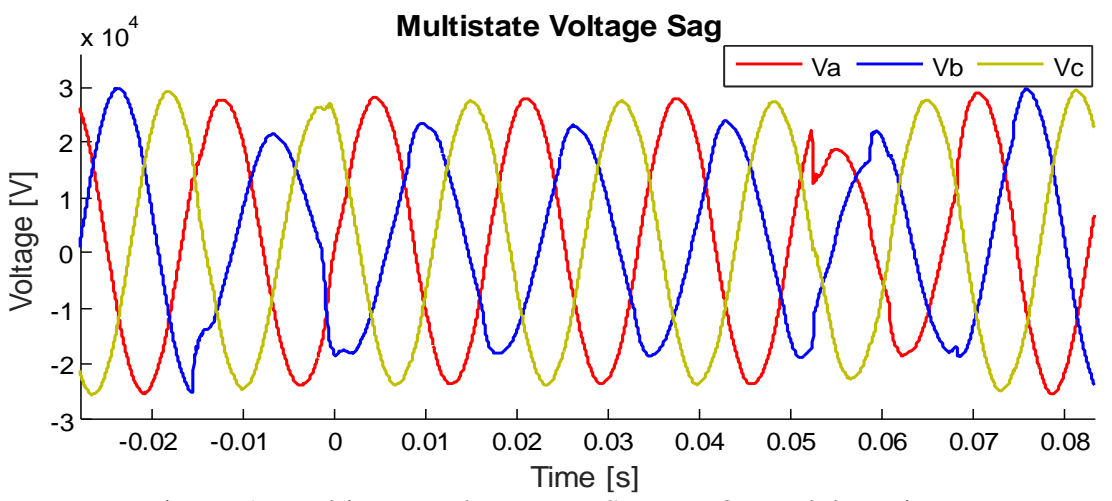

Figure 1. Multistate voltage sag. Source. Own elaboration.

For this reason, this research analyzes the calculation of severity and energy indexes of voltage sags by the limitations in the method imposed by the regulations.

For this, a method of voltage tensor analysis is proposed, which verifies the imbalance between phases, the possible existence of several segments and the presence of several affected phases. To verify the validity of the results, a database of waveform has been analyzed in the substation bar of an industrial circuit.

The article is organized as follows: Section II presents the theoretical framework of this work, section III presents the proposed method of segmentation, classification and characterization of sags, section IV presents the study of real records captured by the network operator, and finally the conclusions of this work give recommendations to analyze voltage sags and its indicators.

\section{Theoretical framework}

In order to analyze the way in which voltage sags are studied, it is fundamental to describe their indicators and the necessary parameters for their computation. Hence, this chapter describes the effective value, duration, residual voltage, severity and energy of voltage sag, according to the IEEE 1564-2014 [1].

\subsection{RMS values of voltage sags}

The rms value is used by [1], [11] to analyze voltage sags. The rms value is calculated every half cycle according to equation (1), where $N$ are the samples per cycle, $k$ is the calculation sample and $v_{\mathrm{i}}$ is the voltage in each sample $i$. Figure 2 shows the RMS values computed using equation (1) for the voltage sag of figure 1.

$$
V_{r m s(1 / 2)}(k)=\sqrt{\frac{1}{N} \sum_{i=1+k-N}^{k} v_{i}^{2}}
$$

The duration and residual voltage of the sags are obtained from the rms value as follows.

\subsection{Residual voltage of sags}

The residual voltage $(V)$ represents the lowest voltage value in a three-phase system during a sag. It is calculated 
from the comparison of the rms values, computed by (1) of each phase.

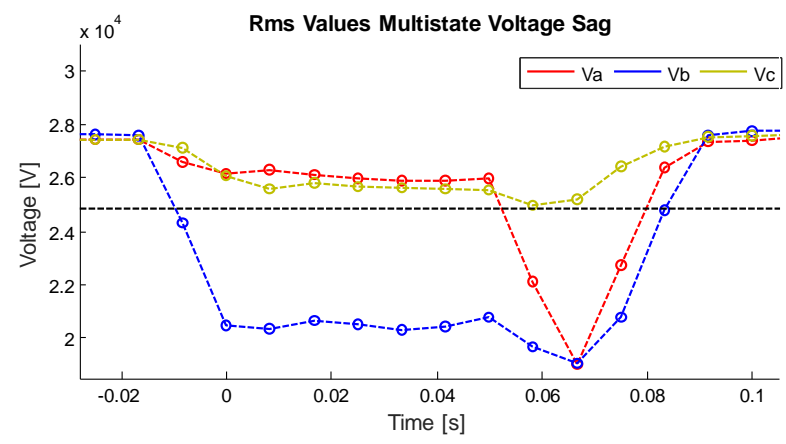

Figure 2. Method of rms values. Source. Own elaboration.

\subsection{Duration of a voltage sag}

The duration $(T)$ represents the time interval in which the system was affected by a voltage sag. It is calculated between the time in which the effective voltage drops below a threshold $(0.9 \mathrm{pu})$ and the time after which all phases exceed it.

\subsection{Energy of a voltage sag}

The IEEE Std 1564 of 2014 [1] describes the indicators for assessing the negative impact of voltage sags.

According to (2), the energy of the sags represents the time equivalent of an interruption in the system compared against the nominal voltage $\left(V_{\text {nom }}\right)$.

$$
E_{v S}=\left[1-\left(\frac{V}{V_{\text {nom }}}\right)^{2}\right] T
$$

The severity of the sags, calculates a dimensionless value that represents the probability of they generating an interruption in industrial processes or electrical equipment. The standard [1] recommends the use of SEMI-F47 for its calculation, as in Table 1.

Table 1. Severity - Curve SEMI F47 [14].

\begin{tabular}{|c|c|}
\hline Duration & Severity computation \\
\hline$T \leq 20 \mathrm{~ms}$ & $\mathrm{~S}_{\mathrm{e}}=1-V$ \\
\hline $20 \mathrm{~ms} \leq T \leq 200 \mathrm{~ms}$ & $\mathrm{~S}_{\mathrm{e}}=2(1-V)$ \\
\hline $200 \mathrm{~ms} \leq T \leq 500 \mathrm{~ms}$ & $\mathrm{~S}_{\mathrm{e}}=3.3(1-V)$ \\
\hline $500 \mathrm{~ms} \leq T \leq 10 \mathrm{~s}$ & $\mathrm{~S}_{\mathrm{e}}=5(1-V)$ \\
\hline$T>10 \mathrm{~s}$ & $\mathrm{~S}_{\mathrm{e}}=10(1-V)$ \\
\hline
\end{tabular}

Source. [14].
The sags indicators are dependent on $V$ and $T$ computed by the rms value. For the sag of Figure 1, a duration of $99.96 \mathrm{~ms}$ is obtained, a residual voltage of $0.65 \mathrm{pu}, \mathrm{E}_{\mathrm{Vs}}$ equal to $56.55 \mathrm{~ms}$ and $\mathrm{S}_{\mathrm{e}}$ is equal to 0.68 .

The calculation of the rms value has delays that can affect the certainty of $T$ and $V$. In addition, the rms value ignores some characteristics of the sags, such as: several affected phases, changes in the residual voltage and imbalance between phases, as has been described in [13-17]. Considering the above, the calculation of the severity and energy indicators of sags can be affected and therefore, the analysis of their effect on the system might be affected too.

\section{Proposed methodology}

In consideration of the deficiencies in the characterization of sags by the rms method, this article proposes a new method of segmentation, classification and characterization to calculate sag indicators. This new proposal is formulated from the tensorial analysis of waveforms, as discussed below.

\subsection{Tensor analysis of waveforms}

From the formulation of a tensor theory of power in the work of Ustariz et al [18], a new tendency to study polyphaser systems has been generated.

This new formulation has been used by Arias et al in [19] in the study of voltage sags. This formulation proposes the study of waveforms by the dyadic product $(\otimes)$ between the first order voltage tensors $\left(\mathrm{u}_{\mathrm{i}}\right)$ and $\left(\mathrm{u}_{\mathrm{j}},\right)_{\text {; }}$; the second order voltage tensor $\left(\Gamma_{\mathrm{ij}}\right)$ is obtained, as follows:

$$
\Gamma_{i j}=u_{i} \otimes u_{j}
$$

The voltage tensors $\left(\mathrm{u}_{\mathrm{i}}\right)$ and $\left(\mathrm{u}_{\mathrm{j}}\right)$ are constructed from the instantaneous values of each phase. In the reference frame $(\boldsymbol{a}, \boldsymbol{b}, \boldsymbol{c})$, the second-order tensor is equal to:

$$
\Gamma_{i j}=\vec{u}_{i} \otimes \vec{u}_{j}=\left[\begin{array}{l}
u_{a} \\
u_{b} \\
u_{c}
\end{array}\right] \otimes\left[\begin{array}{l}
u_{a} \\
u_{b} \\
u_{c}
\end{array}\right]=\left[\begin{array}{lll}
u_{a} u_{a} & u_{a} u_{b} & u_{a} u_{c} \\
u_{b} u_{a} & u_{b} u_{b} & u_{b} u_{c} \\
u_{c} u_{a} & u_{c} u_{b} & u_{c} u_{c}
\end{array}\right]
$$

In this article, we propose to gather in a single indicator the information of all the phases at each instant from the frobenious norm of $\Gamma_{\mathrm{ij}}\left(\lambda_{\Gamma}\right)$, according to equation (5).

$$
\lambda_{\Gamma}=\left\|\Gamma_{i j}\right\|_{F}=\sqrt{\sum_{i=1}^{3} \sum_{j=1}^{3}\left(\Gamma_{i j}\right)^{2}}
$$


Ideally, sinusoidal and balanced conditions, $\lambda_{\Gamma}$ must have a quasi-static behavior, with an average value equal to three times the nominal squared voltage $3 \mathrm{~V}_{\text {nom }}{ }^{2}$. In the event of a disturbance, oscillations representing the alteration of the system are presented. As an example, Figure 3 presents $\lambda_{\Gamma}$ calculated for the sag of Figure 1.

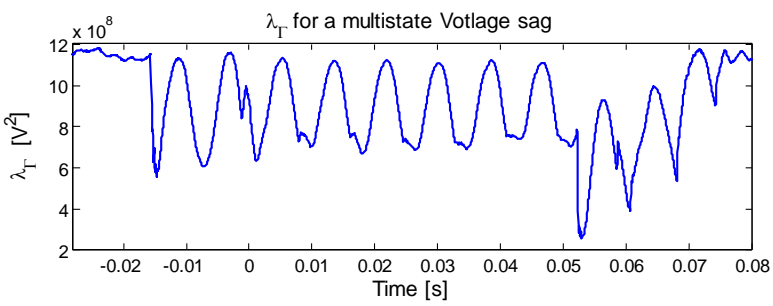

Figure 3. $\lambda_{\Gamma}$ for a multistate sag. Source. Own elaboration.

This behavior is used to perform the segmentation, classification and characterization of the sinking, as shown in Figure 4.

\begin{tabular}{|l|c|}
\hline In: & \multicolumn{1}{c}{ Segmentation } \\
\hline - Tensor assessment combined with \\
residual segmentation \\
Out: & Segment $_{1}, \ldots$, Segment $_{n}$ \\
$\begin{array}{c}\downarrow \\
\text { Classification }\end{array}$
\end{tabular}

\begin{tabular}{|l|l|l}
\hline In: $\quad \lambda_{\Gamma},\left[\right.$ Segment $_{1}:$ Segment $\left._{\mathrm{i}}\right]$ \\
\hline $\begin{array}{l}\text { Verify decision rules to identify class } \\
\text { of voltaje sag }\end{array}$ \\
\hline Out: \\
$\qquad \begin{array}{c}n_{\phi}, \mathrm{U}_{f} \\
\text { Voltage sag index computation }\end{array}$ \\
\hline
\end{tabular}

\begin{tabular}{|l|}
\hline In: $\quad n_{\phi}, U_{f},\left[\right.$ Segment $_{1}:$ Segment $\left._{\mathrm{i}}\right]$ \\
\hline $\begin{array}{c}\text { Voltage sag index computation } \\
T E_{V S}=E_{V S_{-} 1}+\cdots+E_{V S_{-} n}\end{array}$ \\
\hline Out: $\quad$ Energy of the voltage sag \\
\hline
\end{tabular}

Figure 4. Proposed methodology. Source. Own elaboration.

Each stage of the proposed methodology is described below:

\subsection{Segmentation stage}

To perform the analysis of $\lambda_{\Gamma}$, its components are disaggregated by a Kalman filter. Equation (6) presents the decomposition in the direct component and the sum of sinusoidal components of fundamental frequency and harmonics of $\lambda \Gamma$.

$$
\lambda_{\Gamma(t)}=A_{0}+\sum_{n=1}^{N} A_{n}(t) \cos \left(n \omega_{0} t+\theta_{n}(t)\right)
$$

In this work, a Kalman filter with an adaptive function is used in the covariance calculation step of the model error. This modification allows to improve the speed of convergence in the presence of transient changes, as in works [9] and [12].

The difference between $\lambda_{\Gamma}$ and the filter estimate $\left(\lambda_{\Gamma \mathrm{k}}\right)$ is used to detect transient changes from a detection index (DI). This index is calculated, as shown in equation (7), with a moving average of one quarter of a cycle $(\mathrm{W}=8)$. The threshold is calculated with a moving average of half cycle $(\mathrm{V}=2)$, to avoid the identification of false segments in the presence of noise, as presented in equation (8).

$$
\begin{gathered}
\operatorname{dif}(t)=\lambda_{\wp(t)}-\lambda_{\wp k(t)}, \quad D I(n)=\left(\frac{1}{W} \sum_{i=n-W}^{n} \varepsilon(i)\right)^{2} \\
\operatorname{Threshold}(n)=4 \cdot \frac{1}{V} \sum_{i=n-V}^{n+V} \operatorname{dif}(i)
\end{gathered}
$$

DI and Threshold allow to identify the transient changes in measured waveforms, with a high degree of certainty. Therefore, every change that occurs in the sag is detected. The proposed method has identified three segments for the sinking of Figure 1 as shown in Figure 5. The duration of all sinking is obtained as the sum of each segment and is equal to $75.96 \mathrm{~ms}$ for this particular case.

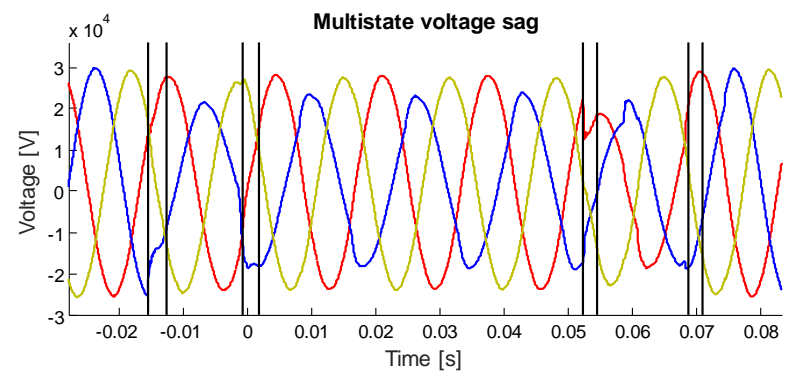

Figure 5. Segmentation results. Source. Own elaboration. 
Additionally, the proposed method differentiates the segments of the multistate sink, and allows to classify each segment separately.

\subsection{Classification stage}

In this proposal, the classification is performed in each identified segment of the sag. In addition, it has been identified that the proposed indicator $\lambda_{\Gamma}$, has a relation with the residual voltage $(V)$, the effective nominal voltage $\left(V_{\text {nom }}\right)$ and the sag class, as listed in Table 2.

Three-phase sags have a constant value of $\lambda_{\Gamma}$. Thus, if the ratio between the maximum and minimum values ( $\left.\lambda_{\Gamma \max }, \lambda_{\Gamma \mathrm{min}}\right)$ is close to 1 , the sag is classified as 3 phase. A threshold of 0.8 is used in the presence of noise in the signal or unbalances that generate a small oscillation of $\lambda_{\Gamma}$.

Table 2. Relation of $\lambda_{\Gamma}$ and sag class.

\begin{tabular}{|c|c|c|}
\hline \multicolumn{3}{|c|}{ Tensor asssessment of voltage sags } \\
\hline Affecthed phases & $\lambda_{\Gamma \max }$ & $\lambda_{\Gamma \text { min }}$ \\
\hline 1 phase sag & $3 V_{\text {nom }}{ }^{2}$ & $V_{\text {nom }}{ }^{2}\left(2 V^{2}+1\right)$ \\
\hline 2 phase sag & $V_{\text {nom }}{ }^{2}\left(V^{2}+2\right)$ & $3 V_{\text {nom }}{ }^{2} V^{2}$ \\
\hline 3 phase sag & $3 V_{\text {nom }}{ }^{2} V^{2}$ & $3 V_{\text {nom }}{ }^{2} V^{2}$ \\
\hline
\end{tabular}

Source. Own elaboration.

Subsequently, 1 phase and 2 phase sags are classified utilizing the magnitudes of column vectors $\Gamma_{\mathrm{ij}}$ (at the time instant of the peak $\left.t_{\lambda \Gamma_{\max }}\right)$. The 2 phase sags are associated to the unaffected phase with the greatest magnitude at $t_{\lambda} \Gamma_{\max }$. The vectors associated with the affected phases have an equal magnitude.

For 1 phase sag, at $t_{\lambda \Gamma_{\max }}$ the vector with the smallest magnitude is related with the affected phase, and is almost equal to zero. Simultaneously, the vectors with the unaffected phases have a similar magnitude. This behavior is presented in Figure 6.

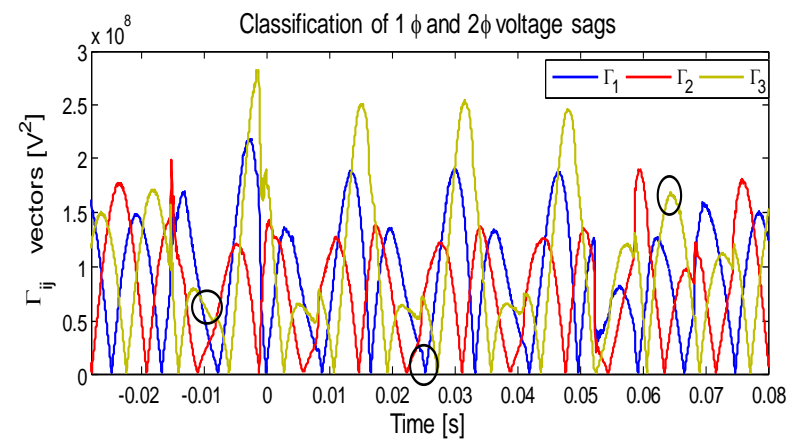

Figure $6 . \Gamma_{\mathrm{ij}}$ vectors multistate sag. Source. Own elaboration.
From minimum magnitude $|\mathrm{d}|_{\min }$, maximum $|\mathrm{d}|_{\max }$ and remaining $|\mathrm{d}|_{\mathrm{s}}$ vectors, the identification of affected phases is performed according to the following:

1) If $\lambda_{\Gamma \min } / \lambda_{\Gamma \max }$ is greater than 0.8 , the sag is classified as 3-phase.

2) If $|\mathrm{d}|_{\max } /|\mathrm{d}|_{\mathrm{s}}$ is less than 2 and $|\mathrm{d}|_{\min }<1$, the sag is classified as 1 phase. In this case the affected phase is considered to be related with the vector with minimum magnitude $|\mathrm{d}|_{\min }$.

3) If the above is false and the ratio $|\mathrm{d}|_{\min } /|\mathrm{d}|_{\mathrm{s}}$ is almost equal to 1 , the sag is classified as 2 phase. In this case the unaffected phase is related with the vector of the maximum magnitude $|\mathrm{d}|_{\max }$.

From the sag class for each segment, $\mathrm{V}$ is cleared using the relation from Table 2 .

\subsection{Voltage sag indicators}

In this paper, it is proposed to consider the characteristics of each segment $(n)$ and to determine the energy not supplied as the sum of the energy loss in each segment, as shown in equation (9)

$$
\begin{aligned}
& T E_{V S}=E_{V S_{-} 1}+\cdots+E_{V S_{-} n} \\
& E_{V S_{-} n}=n_{\phi}\left[1-\left(\frac{V}{V_{n o m}}\right)^{2}\right] T
\end{aligned}
$$

For the sag of Figure 1, the energy calculated with this parameter is $63.94 \mathrm{~ms}$ as shown in Table 3 .

Moreover, the concept of severity has been constructed from a single-phase analysis. Therefore, it ignores the dynamic characteristics of the sag.

Table 3. Multistate voltage sag - total energy loss.

\begin{tabular}{|c|c|c|c|c|}
\hline Segment & $\begin{array}{c}\text { Duration } \\
\boldsymbol{T}[\mathrm{ms}]\end{array}$ & $\begin{array}{c}\text { Residual } \\
\text { voltage } \\
\boldsymbol{V} \text { [pu] }\end{array}$ & $\begin{array}{c}\text { of } \\
\text { affecthed } \\
\text { phases } \\
\text { n } \phi\end{array}$ & $\begin{array}{c}\text { Total sag } \\
\text { energy loss } \\
\text { [ms] }\end{array}$ \\
\hline Primero & 11.81 & 0.71 & 2 & 11.71 \\
\hline Segundo & 50.06 & 0.58 & 1 & 33.21 \\
\hline Tercero & 14.09 & 0.57 & 2 & 19.02 \\
\hline \multicolumn{2}{|c|}{ Total sag energy loss $T E_{V S}[\mathrm{~ms}]$} & 63.94 \\
\hline
\end{tabular}

Source. Own elaboration. 
For this reason, this article proposes to use the total sag energy loss indicator as the only parameter of sags analysis. In this way, it is possible to dimension the impact of the sags in the system as the energy not supplied in the three phases

\section{Results}

A total of 197 voltage sags recorded by the network operator were analyzed. 129 of these sags are monostate and 68 multistate.

With the rms method, only the duration and residual voltage of the sags were obtained, as listed in Table 4 . The rms value method ignores the multistate characteristic of the sags. Applying the severity equation imposed by the regulations, a total energy equivalent to an interruption of 5.6 seconds is obtained.

Table 4. Duration and residual voltage - RMS method.

\begin{tabular}{|c|c|c|}
\hline \multirow{2}{*}{$\begin{array}{c}\text { Residual voltage } \\
\text { (pu) }\end{array}$} & \multicolumn{2}{|c|}{ Duration (s) } \\
\cline { 2 - 3 } & $<\mathbf{0 . 1}$ & $\mathbf{0 . 1 - 0 . 2 5}$ \\
\hline $0.8-0.9$ & 114 & 16 \\
\hline $0.7-0.8$ & 34 & 9 \\
\hline $0.6-0.7$ & 13 & 6 \\
\hline $0.5-0.6$ & 3 & 1 \\
\hline $0.4-0.5$ & 1 & 0 \\
\hline
\end{tabular}

Source. Own elaboration.

Besides, the proposed method allows to obtain the duration, number of segments, residual voltage and number of affected phases for each voltage sag.

The characterization obtained in Figure 7 is shown for multistate voltage sags. With this method, 129 singlevoltage sags have been correctly identified.

Using the proposed method, a total sag energy loss of 6.75 seconds was obtained considering only the monostate voltage sags. This value reflects that the energy not supplied by the sags is greater than the estimated by the rms values method.

One reason for this difference is the ignorance of the number of affected phases. From the classification obtained by the proposed method it has been identified that 60 sags are 1 phase, 562 phase and 133 phase, as shown in Figure 7.

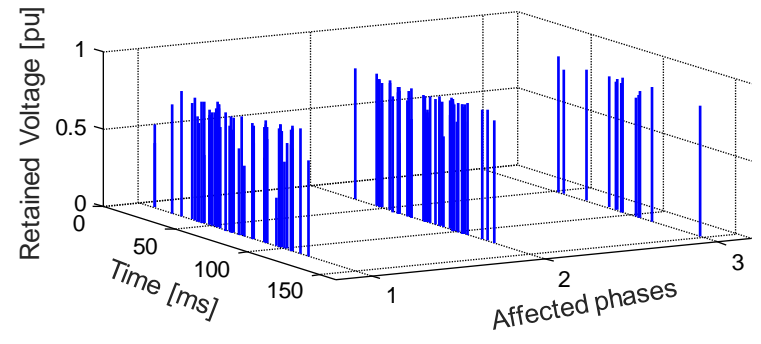

Figure 7. Characterization obtained - monostate voltage sags. Source. Own elaboration.

For the 68 multi-state voltage sags, 52 were identified with at least two stationary segments of different residual voltage and number of affected phases. In Table 5, two sample records and the results of the energy indicators calculated by both methods are listed. In Figure 8 and Figure 9, both records are shown where it is seen that they have several affected phases and several segments.

These sags are an example where the energy computation error can reach more than $200 \%$ by not considering the affected phases and the number of segments.

Table 5. Assessment of multistate voltage sag energy index.

\begin{tabular}{|c|c|c|c|}
\hline \multirow{2}{*}{ Record } & \multicolumn{2}{|c|}{ Sag energy loss [ms] } & \multirow{2}{*}{ Error [\%] } \\
\cline { 2 - 3 } & Regulation & Proposed method & \\
\hline 1 & 92.24 & 223.93 & $242 \%$ \\
\hline 2 & 60.06 & 111.61 & 185.83 \\
\hline
\end{tabular}

Source. Own elaboration.

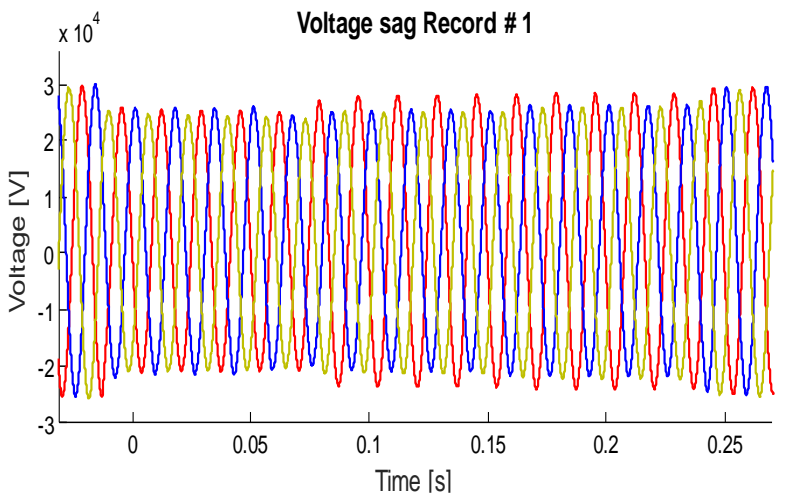

Figure 8. Multistate sag - record 1. Source. Own elaboration. 


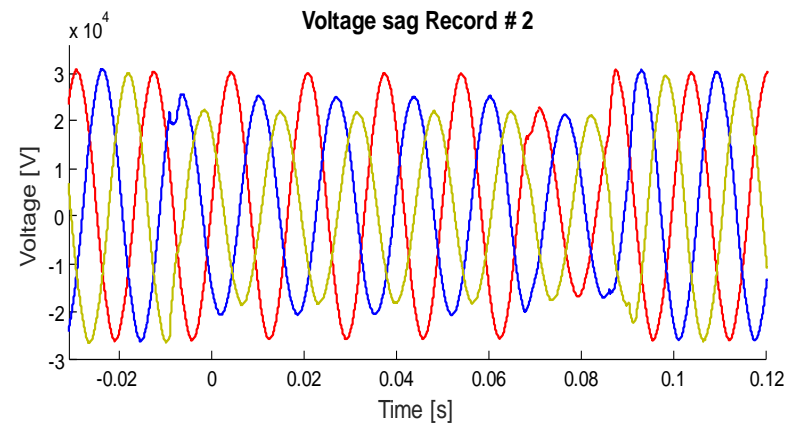

Figure 9. Multistate sag - record 2. Source. Own elaboration.

The total sag energy loss for the total of the multi-state sags is 5 seconds.

By summing the energy loss for the single-state and multi-state sags with the proposed method, it is equivalent to an interruption of 11.75 seconds.

This value reflects the true impact of voltage sags in the system, a scenario that is not reflected by the method imposed by the regulations.

\section{Conclusions and recommendations}

A new method to energy index calculation has been proposed. Energy loss from the voltage sags influence has been computed through conventional and proposed methods.

Differences between energy loss computed by normative methodology and proposed methodology are remarkable. It has been detected that the number of sags with several affected phases can represent more than $50 \%$ of recorded sags. In addition, it has been verified that the multi-state sags represents $30 \%$ of the sags registered in a year. Worse still, although their amount is smaller, the total energy loss by these sags is equivalent to the monostate amount records. This information is not reflected in the results of the effective value method.

For the sags shown in Figures 1, 8 and 9, the rms value method ignores the transient change and the time interval in which several phases are affected. For the calculation of energy, this is reflected in an error rate that reaches $200 \%$.

It is concluded that the method of assessment of sags that try to take account of voltage sag dynamic behavior should also include characteristics of duration, number of segments, residual voltage and number of affected phases for each sag.
Additionally, the difference between indices computed through proposed and conventional methodology show the need of additional studies about accuracy and veracity of voltage sags indices.

An implementation of this type of studies in large power systems that can be monitored in different points is necessary to assess global indices computed by alternative methodologies.

\section{Acknowledgment}

The authors thank Universidad Nacional de Colombia and the research group on Distribution and Power System Networks - GREDyP. Research group on Power Quality and Power Electronics - GICEP. Some tests were developed with the support of the Laboratory of Quality of Energy and Power Electronics - LACEP, of the same institution. In addition, we would like to thank the Caldas Hydroelectric Power Station (CHEC) for providing the equipment and sufficient information on the power quality records for this study.

\section{References}

[1] IEEE Guide for Voltage Sag Indices, IEEE Std 1564-2014, 2014.

[2] A. Bendre, D. Divan, W. Kranz and W. E. Brumsickle, "Are voltage sags destroying equipment?," in IEEE Industry Applications Magazine, vol. 12, no. 4, pp. 12-21, 2006. doi: 10.1109/MIA.2006.1678326

[3] A. dos Santos and M. T. Correia de Barros, "Predicting Equipment Outages Due to Voltage Sags," IEEE Transactions on Power Delivery, vol. 31, no. 4, pp. 1683-1691, 2016. doi: 10.1109/TPWRD.2015.2504352

[4] I. Gu and M. Bollen, Signal processing of Power Quality Disturbances $1^{\text {ra }}$ ed. New Jersey, USA: John Wiley and Sons Ltd, 2006.

[5] J. Y. Chan and J. V. Milanovic, "Severity Indices for Assessment of Equipment Sensitivity to Voltage Sags and Short Interruptions," 2007 IEEE Power Engineering Society General Meeting, Tampa, FL, 2007, pp. 1-7. doi: 10.1109/PES.2007.385457

[6] H. Liao, S. Abdelrahman, Y. Guo and J. V. Milanović, "Identification of Weak Areas of Power Network Based on Exposure to Voltage Sags-Part I: Development of Sag Severity Index for Single-Event Characterization," IEEE Transactions on Power Delivery, vol. 30, no. 6, pp. 2392-2400, 2015. doi: 10.1109/TPWRD.2014.2362965 
[7] H. Liao, S. Abdelrahman, Y. Guo and J. V. Milanović, "Identification of Weak Areas of Network Based on Exposure to Voltage Sags-Part II: Assessment of Network Performance Using Sag Severity Index," IEEE Transactions on Power Delivery, vol. 30, no. 6, pp. 2401-2409, 2015. doi: 10.1109/TPWRD.2014.2362957

[8] S. Z. Djokic and J. V. Milanovic, "Advanced voltage sag characterisation. Part I: Phase shift," IEE Proceedings - Generation, Transmission and Distribution, vol. 153, no. 4, pp. 423-430, 13 July 2006. doi: 10.1049/ip-gtd:20050350

[9] S. Z. Djokic, J. V. Milanovi!c and S. M. Rowland, "Advanced voltage sag characterisation II: point on wave," IET Generation, Transmission \& Distribution, vol. 1, no. 1, pp. 146-154, January 2007.

doi: 10.1049/iet-gtd:20050434

[10] E. Cabezas-Jaimes "Optimal placement of voltage sag meters in distribution networks using fault location constains" SICEL, Bucaramanga, 2017, pp 253-261.

[11] IEEE Recommended Practice for Monitoring Electric Power Quality, IEEE Standard 1159, 2009.

[12] T. C. de Oliveira, J. M. de Carvalho Filho, R. C. Leborgne, G. T. Watanabe, J. P. G. de Abreu and J. F. de Oliveira, "Analysis of the relation between voltage sags severity and fault characteristics," Proceedings of 14th International Conference on Harmonics and Quality of Power - ICHQP 2010, Bergamo, 2010, pp. 1-8. doi: 10.1109/ICHQP.2010.5625498

[13] S. Arias-Guzman, A. J. Ustariz-Farfan and E. CanoPlata, "Segmentation and characterization of voltage sags in the analysis of industrial circuits," 2016 IEEE Industry Applications Society Annual Meeting, Portland, OR, 2016, pp. 1-8. doi: 10.1109/IAS.2016.7731944.

[14] D. Gallo, C. Landi and M. Luiso, "Accuracy Analysis of Algorithms Adopted in Voltage Dip Measurements," IEEE Transactions on Instrumentation and Measurement, vol. 59, no. 10, pp. 2652-2659, Oct. 2010. doi: 10.1109/TIM.2010.2045256.

[15] M. Caujolle, M. Petit, G. Fleury and L. Berthet, "Impact of Waveform Segmentation Accuracy on Disturbance Recognition Reliability," Proc of IPST, Delf, Holanda, 2011.

[16] M. Bollen and Ying Wang, "Voltage sag indices future directions," 2015 IEEE Power \& Energy Society General Meeting, Denver, CO, 2015, pp. 1-13. doi: 10.1109/PESGM.2015.7286188
[17] S. Arias-Guzman, A. J. Ustariz-Farfan, E. A. C. Plata and A. F. Salazar-Jimenez, "Implementation of IEEE Std 1564-2014 for voltage sag severity analysis on a medium voltage substation," 2015 IEEE Workshop on Power Electronics and Power Quality Applications (PEPQA), Bogota, 2015, pp. 1-6. doi: 10.1109/PEPQA.2015.7168222

[18] A. J. Ustariz-Farfán, "Formulación de una teoría tensorial de la potencia eléctrica: aplicaciones al estudio de la calidad de la energía," Ph.D. dissertation, Universidad Nacional de Colombia- sede Manizales, 2011.

[19] S. Arias-Guzmán, "Hundimientos de tensión: un enfoque de análisis a partir del álgebra tensorial," trabajo de fin de máster, Universidad Nacional de Colombia sede Manizales, 2015. 